\title{
VIEIRA, Miriam Steffen. 2011. Categorias jurídicas e violência sexual: uma negociação com múltiplos atores
}

\section{Welliton Caixeta Maciel}

\section{(2) OpenEdition Journals}

Edição electrónica

URL: http://journals.openedition.org/aa/453

DOI: $10.4000 /$ aa. 453

ISSN: 2357-738X

Editora

Programa de Pós-Graduação em Antropologia Social (UnB)

\section{Edição impressa}

Data de publição: 1 junho 2013

Paginação: 275-280

ISSN: 0102-4302

\section{Refêrencia eletrónica}

Welliton Caixeta Maciel, «VIEIRA, Miriam Steffen. 2011. Categorias jurídicas e violência sexual: uma negociação com múltiplos atores», Anuário Antropológico [Online], v.38 n.1 | 2013, posto online no dia 01 outubro 2013, consultado o 28 abril 2021. URL: http://journals.openedition.org/aa/453 ; DOI: https://doi.org/10.4000/aa.453

\section{(c)}

Anuário Antropológico is licensed under a Creative Commons Atribuição-Uso Não-Comercial-Proibição de realização de Obras Derivadas 4.0 International. 


\title{
VIEIRA, Miriam Steffen. 2011. Categorias jurídicas e violência sexual: uma negociação com múltiplos atores. Porto Alegre: Editora da UFRGS. 184 pp.
}

\author{
Welliton Caixeta Maciel \\ PPGAS/UnB
}

Categorias jurídicas e violência sexual: uma negociação com múltiplos atores não é apenas uma etnografia de arquivos e documentos, mas uma etnografia das práticas de justiça e do uso das leis, que percorre a trajetória dos registros policiais da Delegacia da Mulher de Porto Alegre. A etnografia cobre desde o atendimento ao público com a triagem no balcão, passando pelos registros escritos, fluxos e filtros do sistema de justiça criminal, até a sentença ou a decisão final. Revelamse, assim, a complexidade das interações sociais e as negociações entre lei, clientes e operadores do direito, ${ }^{1}$ capazes de transformar a experiência vivida dos agentes envolvidos (personagens, protagonistas e/ou coadjuvantes, civis e institucionais) a partir da classificação, da produção de sentidos, das sensibilidades e da absorção (ou não) de categorias próprias e compreensíveis ao/do/no mundo do direito ${ }^{2}$ no tocante à violência sexual contra a mulher.

O livro da antropóloga, pesquisadora associada do Núcleo de Antropologia e Cidadania (NACi) da Universidade Federal do Rio Grande do Sul (UFRGS), docente na Universidade de Cabo Verde (Uni-CV) e na Universidade do Vale do Rio dos Sinos (Unisinos), professora Miriam Steffen Vieira, é resultado de intensa pesquisa de campo que culminou, primeiramente, em sua tese de doutorado em Antropologia Social, intitulada Universo legal em ato: a construção de categorias jurídicas em torno da violência sexual, defendida em julho de 2007, junto ao Programa de Pós-Graduação em Antropologia Social da UFRGS, sob a orientação da professora Dra. Claudia Lee Williams Fonseca, estando dividida em cinco capítulos, além das partes introdutória e conclusiva, tal como dispostas na tese.

Ao tratar de tema tão pertinente e atual, Miriam revela bastante propriedade sobre os estudos de gênero, violência, polícia, sistemas de justiça e direitos, perceptível na aprofundada análise crítica dos processos sociais sobre os quais reflete, evidenciando a multiplicidade de significados, representações e sentidos atribuídos às concepções acerca dos crimes sexuais, a partir do tratamento que lhes é dado no campo jurídico ${ }^{3}$ e fora dele, além daquelas presentes na sociedade 
de forma mais ampla. Mostra-se também bastante atenta à complexidade da questão da codificação dos sentidos das palavras, evitando o aprisionamento do sentido $^{4}$ ao entender que a violência sexual não compreende uma única definição, mas um processo social que envolve diferentes historicidades, tensões e trajetórias políticas e sociais.

Interessa à autora verificar o modo como a sexualidade entra para a justiça, especificamente a partir de denúncias realizadas por mulheres, levando em consideração o processo histórico que gerou esse campo de atuação especializado, "principalmente pela longeva atuação feminista para a visibilidade e denúncia da violência contra as mulheres, a partir de fins dos anos 1970. Este fator deu origem a políticas públicas e mudanças legais, cujo marco mais recente é a chamada Lei "Maria da Penha" (Lei n $\left.{ }^{\circ} 11.340 / 2006\right)$, que criminaliza a violência doméstica e familiar contra as mulheres (Vieira, 2011:9).

Não se trata, portanto, conforme a autora mesma nos diz, de um "trabalho sobre a permeabilidade do judiciário aos princípios feministas, nem sobre a violência contra a mulher em si, mas sim sobre a mise en scène da violência através do processo (prático e discursivo) jurídico" (:12). Para tanto, ela realizou seu trabalho de campo ao longo do segundo semestre de 2004, em algumas visitas feitas em 2005 e no primeiro semestre de 2006 à Delegacia da Mulher de Porto Alegre; com a utilização de etnografia dos boletins de ocorrências (BOs) registrados em 2003. Em momento posterior, concentrou-se na análise de um processo jurídico envolvendo o crime de estupro e na consulta dos arquivos de uma organização não governamental com atuação no campo dos direitos humanos das mulheres.

No primeiro capítulo, ${ }^{5}$ intitulado "Do 'defloramento' ao 'estupro': entre a 'honra das famílias' e os 'direitos humanos das mulheres'”, Miriam discorre sobre a questão da construção jurídica da violência sexual contra mulheres, no que contextualiza dois momentos históricos: em inícios do século XX, com a atuação do Judiciário e a normatividade de crimes contra a "honra das famílias"; e a partir do final dos anos 70, com o desenvolvimento do movimento feminista e a interlocução deste com o Direito, a partir da agenda política que priorizava a questão da violência contra as mulheres - ambos no contexto brasileiro.

Segundo a autora, de 1890 até 1940, os tipos penais “defloramento" e "estupro” estavam entre os principais crimes sexuais que chegavam à Justiça - enquanto o segundo implicava o uso da violência, o primeiro subentendia uma relação entre os envolvidos e o consentimento para a relação sexual - informando lógicas distintas de atuação dos operadores da Justiça vinculadas a uma ideia de "honra" e de "proteção da família”, uma vez que, nesse período, o debate girava em torno da 
questão da "virgindade", da "honestidade" e da "boa conduta" requeridas às mulheres. Raros eram, portanto, os registros de casos de violência sexual. A noção dos "direitos das mulheres" atrelada à atuação de diversos movimentos feministas e de mulheres aparece a partir dos anos 70. Depois dessa contextualização histórica e social, a autora propõe o conceito de "feminismo de direitos", por meio do qual mostra o processo de construção da interlocução com o campo do direito que privilegia, sobretudo, o tema da violência contra a mulher.

No segundo capítulo, ${ }^{6}$ "Concepções das agentes policiais sobre a Delegacia da Mulher e o trabalho que realizam”, Miriam nos apresenta o cotidiano da Delegacia da Mulher de Porto Alegre e como os sujeitos que por lá circulam constroem sentidos e ressignificações para as práticas sociais construídas naquele espaço e tempo, a partir: das hierarquias funcionais e das relações de poder (entre a delegada e as agentes, entre agentes comuns e agentes plantonistas, entre agentes e clientela etc.) atreladas ao espaço físico da delegacia e fora desta; da triagem de casos e dos filtros de discricionariedade que caracterizam a atividade dos operadores do direito; da arbitrariedade das tipificações jurídicas através da ótica das negociações e dos rearranjos possíveis segundo fatos e delitos noticiados; dos entendimentos sobre conflitos de gênero, violências contra mulheres etc.; do papel social da delegacia para além do registro de denúncias e da apuração de crimes, configurando-se como um espaço de disseminação de significações dos direitos e da orientação jurídica às mulheres como prestação de serviço.

Identifica, ainda, outros sentidos que vão sendo construídos nesse espaço, reveladores de ambiguidades em relação ao projeto político das delegacias da mulher, ${ }^{7}$ e também as estratégias de atuação construídas cotidianamente a partir da interação dos sujeitos com o e no universo jurídico, como: a analogia, o contraste, o blefe (:54); o desvelamento das possibilidades e dos limites estabelecidos pelo próprio direito e suas moralidades, por exemplo: 1. para os casos que operam de acordo com a "lógica da suspeição", nos quais são questionados diretamente os envolvidos (interpretados como "homens safados" e "mulheres 171”) quanto à veracidade dos fatos e de seus depoimentos; 2. aqueles operados de acordo com a "lógica da vitimização feminina", os quais requerem denúncias bem fundamentadas com o intuito de produzir efeitos exitosos nas etapas subsequentes do fluxo do sistema de justiça criminal. Em ambos, a autora observa a importância dos aspectos de gênero acerca dos papéis sociais de homens e mulheres para a construção das categorias jurídicas.

Permanecendo nessa mesma discussão no terceiro capítulo, intitulado "Dinâmicas de construção de categorias", Miriam contextualiza o paradigma normativo e criminal vigente no período de realização da pesquisa que instituiu 
os juizados especiais cíveis e criminais destinados ao julgamento de casos de menor potencial ofensivo, e que acabou por abranger e incluir a judicialização da violência contra a mulher no Brasil, qual seja: a Lei n. ${ }^{\circ}$ 9.099/1995. Ressaltese, entretanto, que posteriormente à realização de seu trabalho de campo, com a promulgação da Lei "Maria da Penha" em setembro de 2006, começaram aos poucos a ser implementados os Juizados de Violência Doméstica e Familiar contra a Mulher, e modificados os procedimentos nas delegacias. Apesar da grande resistência por parte de alguns segmentos da sociedade brasileira e dentro do próprio sistema de justiça criminal, a competência pelo processamento e julgamento dos crimes cometidos com violência doméstica e familiar contra a mulher, conforme previsto nessa legislação, afastou a aplicação dos institutos despenalizadores da Lei n. ${ }^{\circ}$ 9.099/1995, estabelecendo medidas protetivas às mulheres em situação de violência doméstica e regulando novos procedimentos policiais, dentre outras providências.

A autora prossegue com sua análise sobre a questão da complexidade da construção das tipificações jurídicas segundo as práticas tecidas no contexto da delegacia e o percurso que tais categorias fazem ao longo do processo judicial. O tom intimista conferido a este capítulo é capaz de transportar o leitor para dentro da delegacia, instruindo-o em relação aos procedimentos a serem tomados a partir da notitia criminis. ${ }^{8}$ Naquele que denomina "universo legal em ato", caracteriza o processo de construção das categorias jurídicas de acordo com as distintas formas de percepção do mundo das regras (:89-90), chamando a atenção do leitor para o fato de que existem "judicialidades que se formam para além do estipulado no código penal, através do registro de fatos que não são crimes, mas que possuem valor em outras contendas jurídicas ou reconhecimento social” (:86).

No quarto capítulo, "Quando a sexualidade entra para a Justiça: construções jurídicas e concepções de violência sexual na Delegacia da Mulher”, Miriam apresenta, a partir da análise de 7.065 boletins de ocorrência registrados pela Delegacia da Mulher de Porto Alegre em 2003, casos de violência sexual praticados contra mulheres e a forma como estes foram enquadrados pelo sistema de justiça criminal gaúcho, alguns dos quais revelaram ambiguidades características da produção das categorias e dos tipos penais como, por exemplo, a invisibilização da questão da violência sexual nas relações conjugais e a incidência do grau de conhecimento entre as partes no processo de identificação e categorização.

No quinto e último capítulo, intitulado "Violência sexual e raça", a autora se ocupa em analisar as classificações raciais nas denúncias e, na sequência, explora um processo judicial referente a um caso de "estupro". Com isso, pontua que, do total de 7.065 registros de ocorrência em 2003, em 33 apareciam narrativas 
de insultos com teor racial e que apenas seis destes foram tipificados como "preconceitos de raça e cor". Tendo em vista esse delineamento da transversalidade de categorias sociais nos sentidos e nas práticas da Justiça, Miriam consegue identificar que alguns crimes ficam subsumidos em uma categoria mais ampla de violência contra a mulher, uma vez que a Delegacia da Mulher acaba filtrando crimes e violações apenas através desse prisma; e aproveita para ressaltar a importância de que diferentes categorias sociais - raça, classe e gênero - sejam também ressignificadas nas práticas da justiça e de seus operadores.

O livro de Miriam Steffen Vieira se soma aos estudos antropológicos que têm enfatizado a importância da atividade policial para a compreensão do desenrolar do processo judicial e do funcionamento do sistema de justiça, mostrando que a criação de delegacias de polícias voltadas para minorias discriminadas, como mulheres, idosos, crianças e adolescentes, é uma invenção brasileira pioneira que se expandiu por outros países na tentativa de impedir a reprodução de preconceitos e desigualdades sociais. Nesta mesma linha de raciocínio, entende Debert (2012:289 $)^{9}$ que, ao manterem suas práticas voltadas para segmentos populacionais específicos, essas delegacias têm a sua atuação orientada pelo pressuposto de que "a universalização de direitos só poderá ser alcançada se a luta pela democratização da sociedade contemplar a particularidade das formas de opressão que caracterizam as experiências de cada um dos diferentes grupos desprivilegiados”.

A perspectiva metodológica clássica do distanciamento e da familiarização para posterior análise e relativização das narrativas e inserções culturais teve fundamental importância para o trabalho de Miriam, que trouxe enorme contribuição para o enriquecimento do debate antropológico, jurídico e social a respeito das formas com que o Estado brasileiro, através da instituição policial e da Justiça e seu ordenamento, tem respondido às demandas sociais relativas à administração institucional de conflitos interpessoais e ao combate da violência sexual contra mulheres.

De forma bastante cuidadosa e lúcida no tratamento do material de campo, Miriam comprova que o lugar da pesquisa etnográfica no fazer antropológico não se limita a uma técnica de coleta de dados, mas é um procedimento com implicações teóricas e práticas específicas que reconhece a temporalidade e a diversidade de maneiras de se analisar o social. Ressalte-se, contudo, que o procedimento analítico escolhido pela autora não se esgota em si mesmo, senão apenas aponta uma dentre outras possibilidades de apreensão dos sentidos atribuídos às práticas sociais e à interatividade presente nas negociações das categorias jurídicas entre clientela, operadores do direito e o próprio mundo do direito. 


\section{Notas}

1. Trata-se de um conceito nativo e também utilizado pela ciência social para se referir a juízes, promotores, escrivães, técnicos judiciários e advogados.

2. Conceito utilizado por: Kant de Lima, Roberto. 2008. Ensaios de Antropologia e de Direito: acesso à justiça e processos institucionais de administração de conflitos e produção da verdade jurídica em uma perspectiva comparada. Rio de Janeiro: Lumen Juris.

3. Sobre a noção de campo jurídico, ver: Bourdieu, Pierre. 2002. O poder simbólico. Rio de Janeiro: Bertrand Brasil.

4. Conceito operado por: SCOTT, Joan. 1988. Gender: a useful category of historical analysis. In: . Gender and the Politics of History. New York: Columbia University Press.

5. Publicado separadamente, logo após a defesa da tese em: VIEIRA, Miriam Steffen. 2007. “Concepções de Violência Sexual e Direitos das Mulheres: do 'Defloramento' ao 'Estupro'”. Cadernos do LEPAARQ - Textos de Antropologia, Arqueologia e Patrimônio, n. 7/8:103-122. Pelotas/RS: Editora da UFPEL.

6. Publicado, também posteriormente à defesa da tese, em: VIEIRA, Miriam Steffen. 2008. "Homologias entre a organização do espaço, relação entre colegas, com a clientela e com a lei em uma Delegacia de Mulheres". Civitas - Revista de Ciências Sociais da Pontifícia Universidade Católica do Rio Grande do Sul, v. 8, n. 3:482-497. Porto Alegre: PUCRS.

7. Para uma visão aprofundada sobre o processo histórico e social de criação das DEAMs, ver: MACHADO, Lia Zanotta. 2010. "A Invenção das Delegacias Especializadas". In: ___. Feminismo em movimento. São Paulo: Editora Francis. Segundo a autora, "a criação das Delegacias Especializadas sobre a Mulher no Brasil na década de oitenta, é uma resposta ao movimento feminista brasileiro e uma invenção brasileira. [...] a primeira delegacia especializada foi criada em 1985 em São Paulo, seguida da progressiva criação de outras delegacias no país até 1995, quando o surgimento de novas delegacias continua mas a intensidade diminui" (:15).

8. Termo nativo conferido à ação de dar conhecimento espontâneo ou provocado, por parte da autoridade policial, de um fato aparentemente criminoso, com base no qual a autoridade inicia as investigações.

9. Cf. DEBERT, Guita. 2012. "Polícia e Delegacias". In: Antônio Carlos de Souza Lima (org.). Antropologia e Direito: temas antropológicos para estudos jurídicos. Rio de Janeiro/ Brasília: ABA/ LACED/ Contra Capa Livraria. 